\title{
Effects of Student-Teacher Relationships on the Problem Behavior Trajectories of Children and Adolescents
}

\author{
Jane Jiyoun Lee ${ }^{1 *}$ and Byoungduk Sohn ${ }^{2}$ \\ ${ }^{1}$ Department of Education, University of Oxford, UK \\ ${ }^{2}$ Department of Social Work, Chongshin University, Republic of Korea
}

Submission: April 02, 2020 Published: May 04, 2020

*Corresponding author: Jane Jiyoun Lee, Department of Education, University of Oxford, 15 Norham Gardens, Oxford OX2 6PY, UK

\begin{abstract}
The purpose of this study is to investigate whether there are moderating effects of student-teacher relationships on the problem behavior trajectories of children using the Millennium Cohort Study (MCS), a nationally representative longitudinal survey following the development of over 19,000 UK children. Latent growth curve (LGC) modeling within the Structural Equation Modeling (SEM) was employed with an analytic sample of 11,796 children. First, findings suggest that children's problem behavior decreases linearly over time, but that significant levels of individual variations exist. Second, the findings also show that children with higher initial problem behavior levels at age three display steeper drops in problem behavior over time than those who have low initial levels of problem behavior. Third, student-teacher relationships and problem behavior have a transactional and negative relationship. Implications for teachers, policy makers, and early intervention designers to improve children's socio-emotional development and lifelong outcomes, and study limitations are further discussed.
\end{abstract}

Keywords: Problem behavior; Student-teacher relationships

Abbreviations: MCS: Millennium Cohort Study; LGC: Latent growth curve; SEM: Structural Equation Modeling

\section{Introduction}

Problem behavior during early childhood is an important antecedent for future developmental maladjustment, which include mental, academic, and economic outcomes in adulthood and beyond [1]. Previous studies demonstrate the stability of problem behaviors throughout development $[2,3]$. The severity and persistence of negative behavior patterns will most likely grow worse if left untreated, not only affecting childhood outcomes, but deteriorating further to chronic problems such as delinquency, substance abuse, unemployment, higher rates of incarceration, higher risk for a psychiatric disorder, and many other complex problems during adulthood [4]. Positive behavior development is widely agreed to be important for wellbeing and positive life outcomes [5]. Despite such predominance, effective and longlasting mechanisms to moderate problem behavior that meets the needs of all children have yet to be established. Given that high levels of problem behavior are confirmed antecedents of adverse life outcomes, it is crucial to find moderators that reduce rather than intensify problem behaviors and help children to achieve their full potential. Past research suggests that certain points of critical periods exist for problem behaviors [6], and that recognizing these time points are important to mediate maladjustive pathways. For instance, during critical periods of development, children may be more malleable to different risk and protective [7]. Factors such as difficult temperamental dimensions [8] or prenatal maternal stress [8] are known as strong biological antecedents of individual differences in problem behavior development [9]. Considering the substantial portion of time children spend in school, it was assumed that teachers may serve as an important role in promoting positive behavioral changes. Teachers are able to manage behavior using developmentally appropriate strategies that adhere to children's different needs [10].

\section{Discussion}

This study focused on the mechanisms by which children's behavior develops over time, and the potential mediating pathways that may alter poor behavioral development. In 
particular, a possible transactional relationship was explored between student-teacher relationships and children's problem behavior. First, examination of problem behavior trends among children indicate that on average, children between ages three and fourteen show linear and negative growth trajectories for problem behavior. Literature attributes the decreasing trend during the early childhood years to advances in self-regulation, perspective-taking, and frustration tolerance capacities developed with the support of positive interactions with caregivers, teachers, and other adult figures. Results pertaining to the initial status and growth rate of problem behavior indicate a significantly negative association between the initial status and growth rate of problem behavior. These results indicate that children with higher levels of problem behavior at onset show steeper drops, while children with lower levels of problem behavior at onset have more gradual drops, suggesting the need to find predictors of onset, or launchers of behavior problems, in order to foster positive behavioral change. Another important point of consideration is that children with higher levels of problem behavior, especially those that are diagnosed to be in the clinical range, tend to receive more attention for their behavioral difficulties [11]. In turn, these children are more likely to be identified and intervened, resulting in the steep drops in problem levels as observed. Conversely, children who display gradual levels of problem behavior are more likely to be overlooked, culminating in stable persistence of difficulties over time. Given that the long-term effects of problem behavior have a negative impact on many domains of an individual's life over time, it is important to direct attention to children who display gradual levels of problem behavior as well, so that they may receive timely and appropriate interventions and treatments. Predictors of onset can be both environmental and individual factors, working in complex and multidimensional paths to initiate and change behavior. These predictors of onset that launch behavior problems are laid down very early in life through dynamic interactions of genetic, biological, and environmental influences [12]. To illustrate, onsets can occur as early as prenatally, as maternal stress is known to affect the fetal brain [8]. Moreover, risks associated with such early launchers are many times co-occurring and cumulative, inducing persistence of difficulties over time. Examining the relationship between student-teacher relationship and problem behavior suggest the presence of transactional effects between the ages of eleven and fourteen, demonstrating that lower problem behavior at age eleven significantly predicted higher quality of student-teacher relationships at age eleven, which then predicted significantly lower problem behavior at age fourteen. These results demonstrate that problem behavior and student teacher relationships reciprocally affect each other, suggesting the importance of searching for ways to foster higher quality studentteacher relationships. Research suggests that goodness-of-fit between the child's temperamental characteristics [13], teachers' skills to adhere to such individual differences [14], high-quality feedback [15], and providing positive emotional support [16] are elements that promote such relationships. Many studies also support the importance of relationships with the teacher during early childhood for future achievement and behavioral adjustment [17]. Moreover, based on the knowledge that children's behavioral patterns influence the quality of interactions between the child and teacher, active supports for children's prosocial behavior during early childhood are needed as well $[18,19]$.

\section{Conclusion}

The findings of this study provide implications for parents, teachers, and practitioners who seek to prevent behavior problems and further difficulties in their children. Further, although it is important to intervene children who are showing severe levels of behavioral problems, the current study findings also show that these children experienced a steep decrease in symptoms, while children experiencing moderate levels of difficulties showed a gradual decrease. Such findings regarding the steady persistence of problem behavior among children who initially had moderate levels of symptoms suggests that these children need attention as well. Results demonstrate that the development of problem behavior can be both intensified and prevented, and that teachers' relationship with students are reciprocally affected by children's problem behavior levels. As such, interventions could promote high-quality relationships between children and teachers, if designed with the aim to decrease problem behavior levels and maladjustment pathways.

\section{References}

1. Kremer KP, Flower A, Huang J, Vaughn MG (2016) Behavior problems and children's academic achievement: a test of growth-curve models with gender and racial differences. Child Youth Serv Rev 67: 95-104.

2. Basten M, Tiemeier H, Althoff RR, Schoot R, Jaddoe VWV, et al. (2016) The stability of problem behavior across the preschool years: An empirical approach in the general population. J Abnorm Child Psychol 44(2): 393-404.

3. Casalin S, Luyten P, Vliegen N, Meurs P (2012) The structure and stability of temperament from infancy to toddlerhood: a one-year prospective study. Infant Behav Dev 35(1): 94-108.

4. Henry KL, Knight KE, Thornberry TP (2012) School disengagement as a predictor of dropout, delinquency, and problem substance use during adolescence and early adulthood. J Youth Adolesc 41(2): 156-166.

5. Svetlova M, Nichols S R, Brownell CA (2010) Toddlers' prosocial behavior: From instrumental to empathic to altruistic helping. Child Dev 81(6): 1814-1827.

6. Doyle O, Harmon CP, Heckman JJ, Tremblay RE (2009) Investing in early human development: Timing and economic efficiency. Econ Hum Biol 7(1): 1-6.

7. Cox MJ, Mills-Koonce R, Propper C, Gariepy JL (2010) Systems theory and cascades in developmental psychopathology. Dev Psychopathol 22(3): 497-506.

8. Rothbart MK, Sheese B, Rueda M, Posner MI (2011) Developing mechanisms of self regulation in early life. Emot Rev 3(2): 207-213.

9. De Pauw SSW, Mervield I, Van Leeuwen KGV (2009) How are traits related to problem behavior in preschoolers? Similarities and contrasts between temperament and personality. J Abnorm Child Psychol 37(3): 309-325. 
10. Webster-Stratton D, Reid MJ, Hammond M (2001) Preventing conduct problems, promoting social competence: A parent and teacher training partnership in Head Start. J Clin Child Psychol 30(3): 238-302.

11. Jensen PS, Goldman E, Offord D, Costello E, Friedman R, et al. (2011) Overlooked and underserved: "Action Signs" for identifying children with unmet mental health needs. Pediatrics 128(5): 970-979.

12. Smith JD, Dishion TJ, Shaw DS, Wilson MN, Winter CC, et al. (2014) Coercive family process and early-onset conduct problems from age 2 to school entry. Dev Psychopathol 26(4): 917-932.

13. Vitiello VE, Moas O, Henderson HA, Greenfield DB, Munis PM (2012) Goodness of fit between children and classrooms: Effects of child temperament and preschool classroom quality on achievement trajectories. Early Education and Development 23(3): 302-322.

14. Churchill SL (2003) Goodness-of-fit in early childhood settings. Early Childhood Education Journal 31(2): 113-118.

15. Pianta RC, Hamre BK, Allen JP (2012) Teacher-student relationships and engagement: Conceptualizing, measuring, and improving the capacity of classroom interactions.
16. Wentzel KR (2009) Students' relationships with teachers as motivational contexts.

17. Myers SS, Pianta RC (2008) Developmental commentary: Individual and contextual influences on student-teacher relationships and children's early problem behaviors. J Clin Child Adolesc Psychol 37(3): 600-608.

18. Mesman J, Stoel R, Bakermans-Kranenburg MJ, van IJzendoorn MH, Juffer F, et al. (2009) Predicting growth curves of early childhood externalizing problems: Differential susceptibility of children with difficult temperament. J Abnorm Child Psychol 37(5): 1063-1075.

19. Neville HJ, Stevens C, Pakulak E, Bell TA, Fanning J, et al. (2013) Familybased training program improves brain function, cognition, and behavior in lower socioeconomic status preschoolers. Proc Natl Acad Sci USA 110(29): 1-6.

\begin{tabular}{l} 
Your next submission with Juniper Publishers \\
will reach you the below assets \\
- Quality Editorial service \\
- Swift Peer Review \\
- Reprints availability \\
- E-prints Service \\
- Manuscript Podcast for convenient understanding \\
- Global attainment for your research \\
- Manuscript accessibility in different formats \\
( Pdf, E-pub, Full Text, Audio) \\
- Unceasing customer service \\
Track the below URL for one-step submission \\
https://juniperpublishers.com/online-submission.php \\
\hline
\end{tabular}


